\title{
Lipid-Lowering Potency and Tolerability of Generic Rosuvastatin in Bulgarian Patients with High and Very High Risk
}

\section{Stefan Naydenov Naydenov, Nikolay Margaritov Runev*, Emil Ivanov Manov, Rabhat Ahmed Shabani and Temenuga Ivanova Donova}

Clinic of Cardiology, Department of Internal Diseases, "Prof. St. Kirkovich", Medical University of Sofia, Bulgaria

\begin{abstract}
Background: Statins are a class of drugs for treatment of dyslipidemias, but they are also known to significantly reduce the cardiovascular morbidity and mortality in patients at high cardiovascular risk.

The objective of our study was to assess the lipid-lowering potency and tolerability of generic rosuvastatin ROSWERA $®$, prescribed to patients at high and very high cardiovascular risk, with or without hypercholesterolemia.

Methods: Forty-five consecutive patients (24 females, 53.3\%), mean age 62 years were included in this prospective study. ROSWERA® was prescribed 10 to $20 \mathrm{mg}$ once in the evening for primary prevention of high-risk patients or secondary prevention of patients with an overt cardiovascular disease. Levels of total cholesterol, LDLcholesterol, HDL-cholesterol, triglycerides, transaminases and creatine kinase were examined at baseline and at months 3, 6, 12. Results: total cholesterol and LDL-cholesterol levels decreased from $6.84 \pm 0.89$ and $4.44 \pm 1.01$ $\mathrm{mmol} / \mathrm{l}$ (baseline) to $5.05 \pm 0.37$ and $2.77 \pm 0.61 \mathrm{mmol} / \mathrm{l}$ (month 12) in patients, treated with ROSWERA $\AA 10 \mathrm{mg}$. The levels of total cholesterol and LDL-cholesterol diminished to $5.30 \pm 0.43$ and $2.84 \pm 0.45 \mathrm{mmol} / \mathrm{l}$ at month 12 in patients, receiving ROSWERA $₫ 20 \mathrm{mg}$. The transaminase and creatine kinase values did not change significantly and no adverse events were reported.
\end{abstract}

Conclusion: The generic rosuvastatin ROSWERA $₫$ at dosage $10 \mathrm{mg}$ and $20 \mathrm{mg}$ daily demonstrated high lipidlowering efficacy and good safety profile in patients at high and very high cardiovascular risk.

Keywords: Generic rosuvastatin; Lipid-lowering potency; High cardiovascular risk

\section{Introduction}

Statins were approved in clinical practice not only for treatment of dyslipidemias, but also as a class of drugs, which could significantly reduce cardiovascular morbidity and mortality in patients with high and very high cardiovascular (CV) risk [1]. According to the Cholesterol Treatment Trialists' Collaboration meta-analysis, including $>170000$ participants from 26 randomized trials, a reduction with $10 \%$ of allcause mortality and with $20 \%$ deaths of coronary artery disease (CAD), as well as a decrease of the risk for major coronary events by $23 \%$ and for stroke by $17 \%$ per $1.0 \mathrm{mmol} / \mathrm{l}(40 \mathrm{mg} / \mathrm{dl})$ low-density lipoprotein cholesterol (LDL-C) reduction were reported $[1,2]$.

Rosuvastatin is marketed as the most potent statin [3]. Data summary of multiple clinical trials revealed that its use is associated with greater reductions in LDL-C across the dose range of 5-40 mg/day than any other currently available statin $[3,4]$. In this dose interval the decrease of LDL-C with rosuvastatin was found to be $43-60 \%$, whereas with atorvastatin 20-80 mg: $42-54 \%$ and simvastatin 20-80 mg: 30-50\%. Moreover, during the therapy with rosuvastatin a significant increase of high-density lipoprotein cholesterol (HDL-C) and reduction of triglycerides (TG) are obtained as well [3-5].

There are data from clinical studies, analyzing the lipid-lowering potency and safety of generic simvastatin, atorvastatin, lovastatin and pravastatin, but such data are still insufficient, regarding generic forms of the original rosuvastatin - CRESTOR ${ }^{\oplus}$ (manufactured by Astra Zeneca) [6-10].

\section{Objective}

The aim of our study was to assess the lipid-lowering potency and tolerability of generic rosuvastatin ROSWERA ${ }^{\star}$ (manufactured by the pharmaceutical company Krka, d.d, Novo mesto, Slovenia), prescribed for treatment, primary or secondary prevention of patients with high and very high CV risk, with or without hypercholesterolemia.

\section{Methods}

Forty five consecutive patients - 24 females (53.3\%) and 21 males, mean age 62 (44-86) years were included in this pilot, non-randomized, uncontrolled, prospective study. All of them were admitted to the Clinic of Cardiology, Department of Internal Diseases "Prof. St. Kirkovich" at "Alexandrovska" University hospital in Sofia, Bulgaria for diagnostic procedures and treatment during the period September 2011-June 2012. The inclusion criteria were indications for statin prescription, as follows:

Primary prevention for high CV risk (10-year's risk for a fatal cardiovascular event $\geq 5 \%$ and $<10 \%$ ), assessed by the European society of cardiology (ESC) heart score (available at http://www.heartscore. org/pages/welcome.aspx) - 28 (62.2\%) patients. The mean ESC heart score of this subgroup was $7.32 \pm 1.22(5-9)$;

Secondary prevention (very high CV risk, ESC heart score $\geq 10 \%$ ) - $17(37.8 \%)$ patients with one or more of the following: $12(26.7 \%)$ -

*Corresponding author: Nikolay Margaritov Runev, Clinic of Cardiology, Department of Internal Diseases, "Prof. St. Kirkovich", Medical University of Sofia 1 St. Georgi Sofiyski Str, Sofia 1431, Bulgaria, Tel: +359 2 9230658; E-mail: nrunev@abv.bg

Received May 08, 2014; Accepted May 31, 2014; Published June 07, 2014

Citation: Naydenov SN, Runev NM, Manov El, Shabani RA, Donova TI (2014) LipidLowering Potency and Tolerability of Generic Rosuvastatin in Bulgarian Patients with High and Very High Risk. J Cardiovasc Dis Diagn 2: 162. doi:10.4172/2329 9517.1000162

Copyright: ( 2014 Naydenov SN, et al. This is an open-access article distributed under the terms of the Creative Commons Attribution License, which permits unrestricted use, distribution, and reproduction in any medium, provided the original author and source are credited. 
Citation: Naydenov SN, Runev NM, Manov EI, Shabani RA, Donova TI (2014) Lipid-Lowering Potency and Tolerability of Generic Rosuvastatin in Bulgarian Patients with High and Very High Risk. J Cardiovasc Dis Diagn 2: 162. doi:10.4172/2329-9517.1000162

prior myocardial infarction, 7 (15.6\%) - stable angina pectoris, 4 (8.9\%) - ischemic cardiomyopathy and $11(24.4 \%)$ - cerebrovascular disease (CVD) The mean ESC heart score of this subgroup was $20.64 \pm 7.47$ (10-34);

Exclusion criteria for our study were contraindications for statin treatment (known allergy to any ingredients of the tablets, severe liver and/or renal failure, rhabdomyolisis, myopathia or another reported adverse event during previous treatment with any rosuvastatin), TC and LDC-C at target levels with another statin, patient's refusal to be treated with the study drug.

The total number of patients, indicated for secondary prevention, exceeded 17 due to the presence of more than one CV disease in some of them.

An initial dose of either 10 or $20 \mathrm{mg}$ of ROSWERA was added to the patient's evening regimens. The choice of statin dosage for primary prevention was based on the baseline and target levels of LDL-C according to the ESC guidelines, consistent with the CV risk profile of the individual patient, concomitant diseases and medication, liver function, previous experience with statin treatment $[11,12]$. The target levels of LDL-C for subjects at high risk were $<2.5 \mathrm{mmol} / \mathrm{L}$ and for veryhigh risk patients $<1.8 \mathrm{mmol} / \mathrm{L}$ or a $\geq 50 \%$ reduction from baseline LDL-C. In patients, whose target LDL-C levels were not achieved by the initial dose of statin and if the statin treatment was well tolerated, the dose was increased at follow-up visits after hospital discharge. The mean follow-up period for the entire group was 5.4 months. The number of patients, followed up for 3 months was 24 (53.3\%) and for 12 months $-21(46.7 \%)$

Nineteen patients $(42.2 \%)$ had previously been treated with another statin before inclusion into the study, but none of them had reached target LDL-C levels.

All patients underwent the following evaluations:

- Risk profile for cardiovascular complications;

- Dynamics of lipid levels: Total cholesterol (TC), LDL-C, HDL-C, triglycerides (TG), aspartate aminotransferase (AST), alanine aminotransferase (ALT), creatine kinase (CK);

- Tolerability (adverse effects during the treatment with ROSWERA ${ }^{\oplus}$, compliance);

- Statistical analysis was accomplished by Statistical Package for the Social Sciences software (SPSS), version 13.0 for Windows and included:

A) Descriptive methods: Variational analysis of quantitative variables (minimal, maximal and mean value, standard deviation) and Frequency analysis of qualitative variables (nominal and ordinal), including absolute, relative and cumulative frequencies (\%)

B) Methods for verification of hypotheses:

- Non-parametric: Chi-square or Fisher's exact test for quantitative categorical variables; Gamma-test for ordinal variables;

- Parametric: Student's T-test for independent samples.

For all tests, $\mathrm{p}<0.05$ was accepted as a level of statistical significance.

\section{Results}

The main CV risk factors (RF), present in our patients are as follows: arterial hypertension (HTN) - in 16 (35.6\%), diabetes mellitus (DM) type 2 - in 13 (28.9\%), smoking - in 21 (46.7\%), overweight (OW), defined as body mass index (BMI) $26-29 \mathrm{~kg} / \mathrm{m}^{2}$ or obesity (BMI $\geq 30$ $\left.\mathrm{kg} / \mathrm{m}^{2}\right)$ - in $26(57.8 \%)$, family predisposition in $25(55.6 \%)$, sedentary lifestyle (SL) - in 17 (37.8\%) (Figure 1).

The patients with three concomitant RF were prevalent - 21 (46.7\%), two RF were found in 13 (28.9\%). Relatively small number of patients had $4 \mathrm{RF}-7$ (15.6\%), $5 \mathrm{RF}-3(6.7 \%)$ and $1 \mathrm{RF}-1$ patient $(2.2 \%)$. The most common combination of RF included: family predisposition to ischemic heart disease (IHD), OW/obesity, HTN and/or SL - in 34 (75.6\%) of patients.

ROSWERA $^{\oplus} 10 \mathrm{mg}$ per day was administered to 33 (73.3\%) of the patients and $20 \mathrm{mg}$ per day were prescribed to $12(26.7 \%)$. There were no differences in daily dose between genders observed" (Figure 2).

The main results of lipid lowering treatment with ROSWERA ${ }^{\circ}$ are presented in Table 1, Figures 3 and 4 . Total cholesterol levels $<5.0$ $\mathrm{mmol} / \mathrm{l}(193.3 \mathrm{mg} / \mathrm{dl})$ were achieved by $30(66.7 \%)$ patients from the general group, whereas 21 (46.7\%) of all patients had reduction of TC $<4.5 \mathrm{mmol} / \mathrm{l}(174.0 \mathrm{mg} / \mathrm{dl})$. Among these ones at high CV risk, levels of LDL-C $<3.0 \mathrm{mmol} / \mathrm{l}(116.0 \mathrm{mg} / \mathrm{dl})$ were achieved by $25(89.3 \%)$ and $<2.5 \mathrm{mmol} / \mathrm{l}(96.7 \mathrm{mg} / \mathrm{dl})$ - by $19(67.9 \%)$ patients. In the group for secondary prevention (very high $\mathrm{CV}$ risk) a reduction of LDL-C $<2.5$ $\mathrm{mmol} / \mathrm{l}(96.7 \mathrm{mg} / \mathrm{dl})$ was obtained in $9(52.9 \%)$ and $<1.8 \mathrm{mmol} / \mathrm{l}(69.6$ $\mathrm{mg} / \mathrm{dl})-$ in $3(17.6 \%)$.

Total cholesterol and LDL-C level decreased from $6.84 \pm 0.89$ $\mathrm{mmol} / \mathrm{l}(264.5 \pm 34.4 \mathrm{mg} / \mathrm{dl})$ and $4.44 \pm 1.01 \mathrm{mmol} / \mathrm{l}(171.7 \pm 39.1 \mathrm{mg} /$

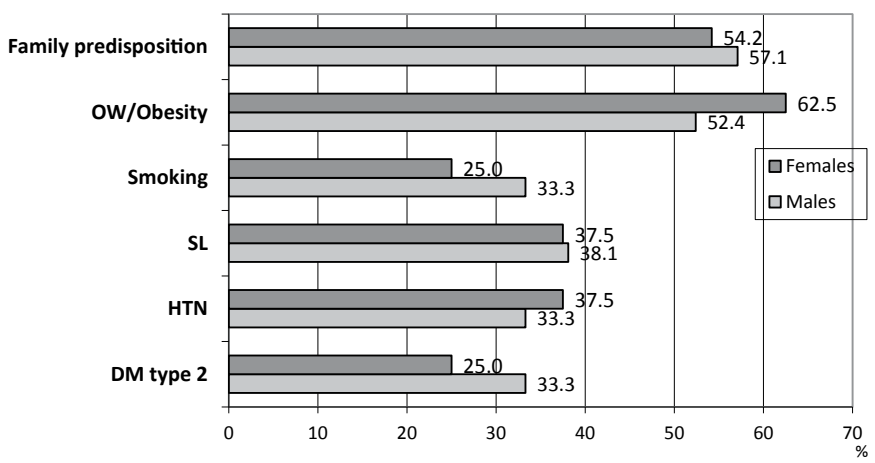

Figure 1: Risk profile of patients in the study: comparison by gender ( $p_{\text {male }}$ females $=\mathrm{NS}$ )

$\%$

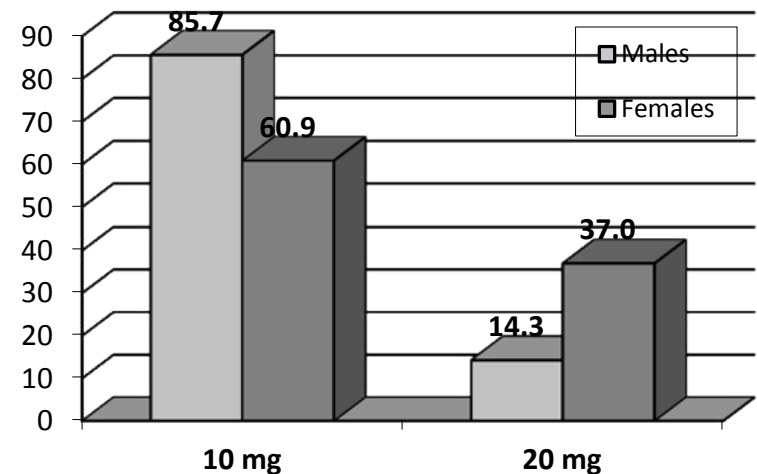

Figure 2: Daily dosage of ROSWERA®: comparison by gender ( $p_{\text {males }}$ $=\mathrm{NS}$ ). 
Citation: Naydenov SN, Runev NM, Manov El, Shabani RA, Donova TI (2014) Lipid-Lowering Potency and Tolerability of Generic Rosuvastatin in Bulgarian Patients with High and Very High Risk. J Cardiovasc Dis Diagn 2: 162. doi:10.4172/2329-9517.1000162

Page 3 of 6

\begin{tabular}{|c|c|c|c|c|c|}
\hline & Parameter & Minim. & Max. & Mean & t. dev. \\
\hline \multicolumn{2}{|r|}{ Total cholesterol } & $4.60(177.9)$ & $\begin{array}{c}9.77 \\
(377.8)\end{array}$ & $6.84(264.5)$ & $0.89(34.4)$ \\
\hline & LDL-C & $20(85.1)$ & $7.90(305.5)$ & 4.44 (171.7) 1. & $1.01(39.1)$ \\
\hline \multicolumn{2}{|r|}{ Triglycerides } & $0.67(59.3)$ & $5.29(468.6)$ & $2.03(179.8) 1$. & \\
\hline \multicolumn{2}{|r|}{ HDL-C } & & $1.90(7$ & & \\
\hline \multicolumn{6}{|c|}{ Baseline } \\
\hline \multirow{4}{*}{$\begin{array}{l}10 \\
\mathrm{mg}\end{array}$} & $\mathrm{rol}$ & 77.9) & $8.20(317.9)$ & 9) & $75(29.4$ \\
\hline & LDL-C & $2.20(85.1)$ & $5.80(224.3) \quad 4$ & $4.31(166.7)$ & $83(32.1)$ \\
\hline & Triglycerides & 0.93 & $5.29(468.6) \quad 2$ & 2.17 (192.2) & 6) \\
\hline & H & 0 & $1.90(73.4)$ & $\begin{array}{c}1.23 \\
(47.6)\end{array}$ & $0.32(12.4)$ \\
\hline \multirow{4}{*}{$\begin{array}{l}20 \\
\mathrm{mg}\end{array}$} & Total chole & 6.27 & 8) 7 & $7.48(289.2)$ & $1.10(42.5)$ \\
\hline & LDL-C & 3.70 & 7.90 & 5.00 & 7.9) \\
\hline & Triglycerides & & 3.80 & 1.92 & 5.9) \\
\hline & & & $1.70(65.7)$ & & \\
\hline \multicolumn{6}{|c|}{ Month 3} \\
\hline \multirow{4}{*}{$\begin{array}{l}10 \\
\mathrm{mg}\end{array}$} & 1 & & 5.70 & & \\
\hline & LDL-C & 7) 3 & 3.20 & 8.7) & 2.8) \\
\hline & Triglycerides & 0) 1 & 8) 1 & 1.50 & 9.2) \\
\hline & HDL- & & 1.70 & & \\
\hline \multirow{4}{*}{$\begin{array}{l}20 \\
\mathrm{mg}\end{array}$} & Total cholesterol & 3) 5 & 5.90 & 5.7) & 7.0) \\
\hline & LDL-C & 2.90 & 4) 3 & .2) & \\
\hline & Triglyceride & 2) 1 & 2) 1 & 4) & 6.9) \\
\hline & & & $1.90(73$ & & .8) \\
\hline \multicolumn{6}{|c|}{ Month 6} \\
\hline \multirow{4}{*}{$\begin{array}{c}10 \\
\text { mg }\end{array}$} & & .8) & 5.9 & & \\
\hline & LDL-C & $(50.7)$ & $4.00(1$ & 2.8 & $3.2)$ \\
\hline & Triglyceride & $0.87(7$ & $1.94(1$ & 1.46 & $1.0)$ \\
\hline & 1חסו & 2) & & 3) & 1.6) \\
\hline \multirow{4}{*}{$\begin{array}{l}20 \\
\mathrm{mg}\end{array}$} & Total cholesterol & $4.70(181.7)$ & $6.34(245.2)$ & 5.36 & 22.0) \\
\hline & LDL-C & $2.70(104.4)$ & $4.50(174.0)$ & 3.30 & (25.5) \\
\hline & Triglycerid & 2) & $1.80(159.4)$ & 6.9) & (39.9) \\
\hline & L-C & 3) & $1.90(73.5)$ & (51.8) & 2.8) \\
\hline \multicolumn{6}{|c|}{ Month 12} \\
\hline \multirow{4}{*}{$\begin{array}{l}10 \\
\mathrm{mg}\end{array}$} & Total ch & 6) & $5.70(220.4)$ & .3) & 0.3 \\
\hline & LDL-C & $1.31(50.7)$ & $3.20(123.7)$ & $2.77(107.1)$ & 0.61 \\
\hline & iglycerid & 10 & & 1.54 & 0.32 \\
\hline & HDL-C & $4(40.2)$ & $57(60.7)$ & $1.19(46.0)$ & $0.19(7.3)$ \\
\hline \multirow{4}{*}{ 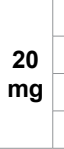 } & Total choleste & $4.92(190.3)$ & $5.90(228.2)$ & $5.30(204.9)$ & 0.43 \\
\hline & LDL-C & $2.90(112.1)$ & $3.94(152.4)$ & $2.84(109.8)$ & 0.45 \\
\hline & Triglycerides & $0.68(93.0)$ & $1.73(153.2)$ & $1.32(116.9)$ & $0.52(46$. \\
\hline & HDL-C & 0.99 (38.3) & $1.90(73.5)$ & $1.41(54.5)$ & $0.46(17$. \\
\hline
\end{tabular}

Table 1: Baseline and follow-up laboratory data in $\mathrm{mmol} / \mathrm{l}(\mathrm{mg} / \mathrm{dL})$.

dl) at baseline to $5.05 \pm 0.3 \mathrm{mmol} / \mathrm{l}(195.3 \pm 11.6 \mathrm{mg} / \mathrm{dl})$ and $2.77 \pm$ $0.61 \mathrm{mmol} / \mathrm{l}(107.1 \pm 23.6 \mathrm{mg} / \mathrm{dl})$, respectively at month 12 in patients, treated with ROSWERA ${ }^{\circ} 10 \mathrm{mg}(\mathrm{p}<0.01)$. The levels of TC and LDL-C diminished to $5.30 \pm 0.43 \mathrm{mmol} / \mathrm{l}(204.9 \pm 16.6 \mathrm{mg} / \mathrm{dl})$ and $2.84 \pm 0.45$ $\mathrm{mmol} / \mathrm{l}(109.8 \pm 17.4 \mathrm{mg} / \mathrm{dl})$, respectively at month 12 in patients, receiving ROSWERA ${ }^{\circ} 20 \mathrm{mg}(\mathrm{p}<0.01)$.

ROSWERA $^{\oplus} 10 \mathrm{mg}$ achieved reduction of TC by $23.1 \%$ at month 3 was found ( $<<0.01$ versus baseline). The TC decrease at months 6 and $12(24.4 \%)$ was comparable to the level of month 3. ROSWERA ${ }^{\circ}$ $10 \mathrm{mg}$ achieved LDL-C reduction of $34.8 \%$ at month 3 ( $\mathrm{p}<0.01$ versus baseline). The LDL-C decrease at 6 and 12 (35.7\%) months was at the level of month 3. With higher dosage of ROSWERA ${ }^{\oplus}(20 \mathrm{mg}$ daily) a better reduction of the lipid parameters, mentioned above, was reached: $28.8 \%$ and $29.1 \%$ for TC, $34.2 \%$ and $43.2 \%$ for LDL-C at months 3 and 12 , respectively, compared to the baseline levels $(\mathrm{p}<0.01)$.
During the follow-up period, no adverse effects, related to the treatment with ROSWERA ${ }^{\circ}$ were observed. Increase of the dosage (from 10 to $20 \mathrm{mg}$ daily) was necessary for 7 patients. There were no significant differences between the levels of transaminases (AST and ALT) and CK, measured at baseline and months 3, 6 and 12 in patients on $10 \mathrm{mg}$ or $20 \mathrm{mg}$ daily (Figures 5 and 6).

\section{Discussion}

Statins are an approved class of drugs with a relatively wide range of indications [1,12-15]. European guidelines for treatment of cardiovascular diseases also suggest that statins should be administered for primary prevention in patients with high CV risk, particularly in diabetics $[11,12,15]$. Patients with overt cardiovascular, cerebrovascular, peripheral arterial diseases or renal impairment are among the groups with greatest benefits of statin therapy (secondary CV prevention) $[1,11]$. It is well known these effects are not only due to lipid-lowering properties of statins but also to their pleiotropic properties $[1,15]$. The CTT clinical trial proved that in secondary prevention statins could reduce 5 -years mortality rate by $20 \%$ for each $1 \mathrm{mmol} / \mathrm{l} \mathrm{LDL-C}$ reduction [2,15]. Two other clinical studies - Incremental Decrease in End point through Aggressive Lipid lowering (IDEAL) and Treating to New Targets (TNT) showed strong linear correlation between the decrease of LDL-C levels below $1.8 \mathrm{mmol} / \mathrm{l}$ and the reduction of $\mathrm{CV}$ risk [15].

The real clinical practice data showed a lot of patients, treated by statins did not achieve the target levels of TC and LDL-C [11]. The possible explanation for most of these cases could be the prescription of inadequate doses of statins away from these ones, approved in the clinical trials. Despite the unsatisfactory results the therapy remains frequently not corrected usually due to the so called therapeutic

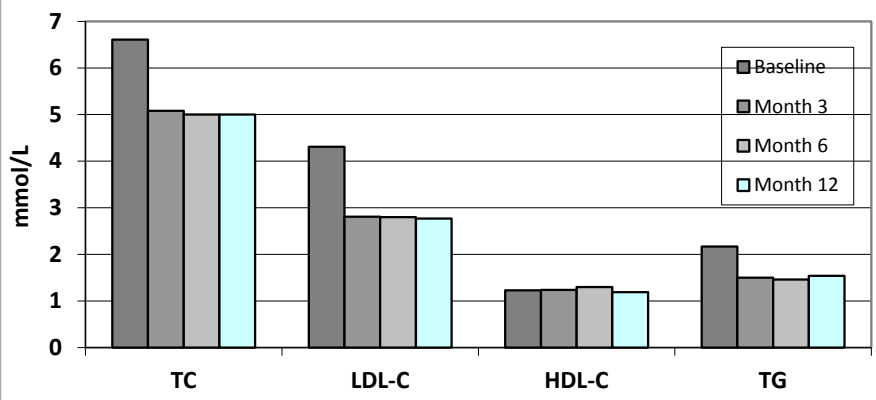

Figure 3: Dynamics in lipid levels in patients, treated with ROSWERA® 10 $\mathrm{mg}(\mathrm{p}<0.05$ only for the baseline levels of TC and LDL-C versus months 3 , 6 and 12).

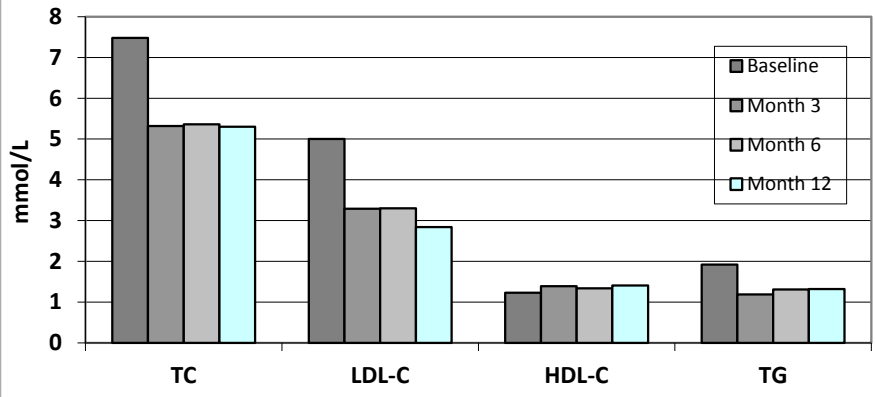

Figure 4: Dynamics in lipid levels in patients, treated with ROSWERA $₫ 20$ $\mathrm{mg}(\mathrm{p}<0.05$ only for the baseline levels of TC and LDL-C versus months 3 , 6 and 12). 
Citation: Naydenov SN, Runev NM, Manov El, Shabani RA, Donova TI (2014) Lipid-Lowering Potency and Tolerability of Generic Rosuvastatin in Bulgarian Patients with High and Very High Risk. J Cardiovasc Dis Diagn 2: 162. doi:10.4172/2329-9517.1000162

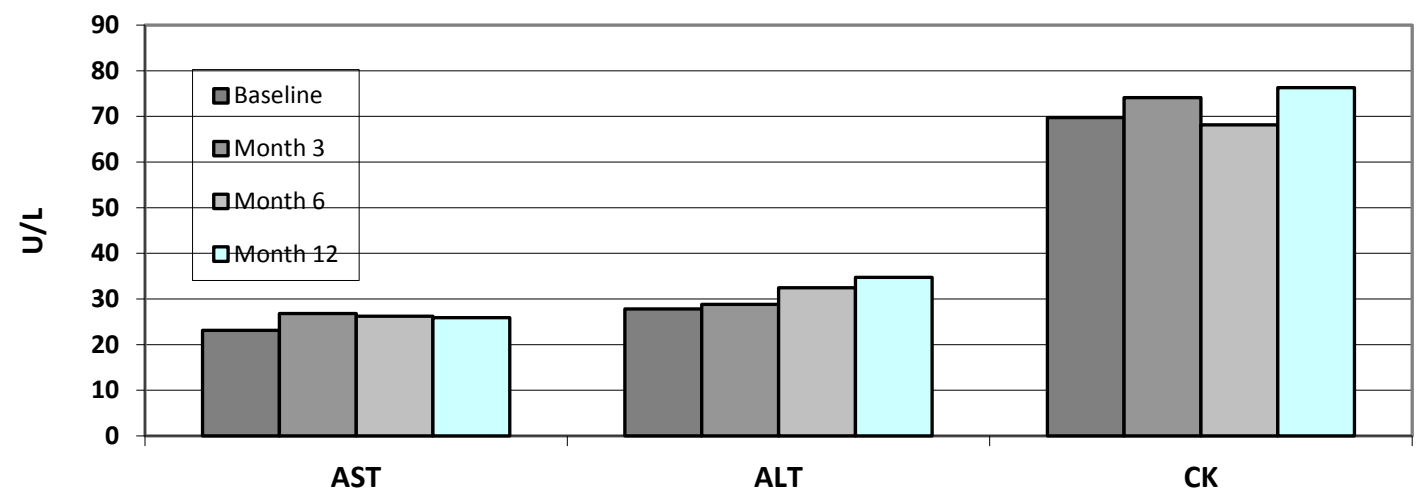

Figure 5: Dynamics of the liver enzymes and CK during the follow-up of the patients, treated with ROSWERA® $10 \mathrm{mg}, \mathrm{p}=\mathrm{non}$-significant (NS).

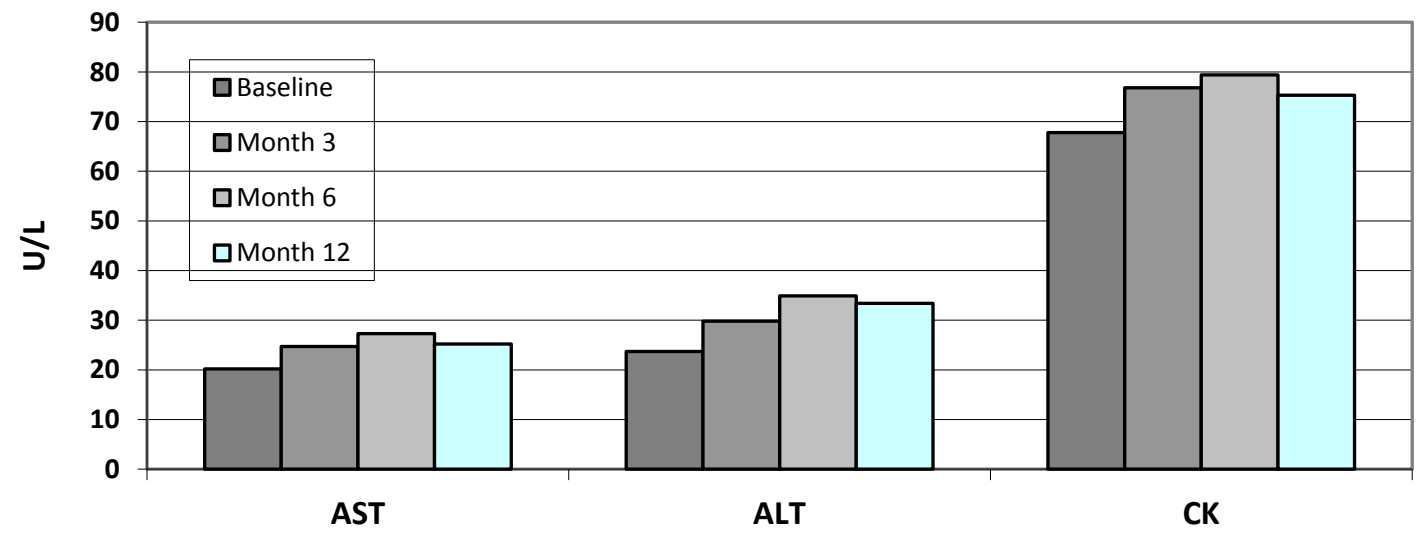

Figure 6: Dynamics of the liver enzymes and CK during the follow-up of the patients, treated with, treated with ROSWERA® $20 \mathrm{mg}$ ( $p=N S$ ).

"inertia" of many physicians or the fear of serious adverse effects. Another possible explanation could be the interruption of statin treatment at a certain moment by the patients. According to our own clinical experience three main reasons for such interruption should be pointed out: 1 . The lack of patient's perception for intermediate benefits of the therapy; 2. Dissatisfaction by the idea for life-long statin treatment; 3 . High price and low reimbursement of some statins by the health funds in some countries, particularly the original forms. The generic forms of these statins being more financially affordable could be a cost-effective solution of the last problem.

Rosuvastatin is the most potent and commonly used statin in clinical practice. Its benefits for primary and secondary prevention have been proven in large international studies (JUPITER, ASTEROID, METEOR) $[2,13,15]$. Our study is a small-sized, pilot, non-randomized, uncontrolled study, aiming to provide some preliminary information about the lipid-lowering efficacy and tolerability of a new generic form of rosuvastatin (ROSWERA *). This statin had recently been introduced in Bulgaria and there was not sufficient data about its clinical effectiveness. For this reason we decided to test the efficacy and safety profile of ROSWERA *, administered for primary prevention of patients with a high CV risk (EuroSCORE $\geq 5 \% \leq 10 \%$ ) as well as for secondary prevention of these ones with previous myocardial infaction, stable angina or cerebrovascular disease. We included patients who had not received statin therapy up to now or had been undergone treatment with other statins, but had not achieved the target levels of TC and LDL-C.
Our results showed statistically significant reduction of both TC and LDL-C levels after the first 3 months of treatment with ROSWERA ${ }^{\circ}$. During the follow-up period (at 6-th and 12-th month) the reached values of TC and LDL-C were practically the same as these ones at 3-rd month. These data supported the findings of Johnes et al. [16], who demonstrated the first dose of statins was accounted for the greatest reduction of LDL-C. The doubling of statin dose leads to additional LDL-C decrease by only $6 \%$.

On the other side, the number of patients, achieving the target levels of LDL-C (at month 12: 35.7\% with 10 mg ROSWERA ${ }^{\oplus}$ and $43.2 \%$ with $20 \mathrm{mg}$ ) was comparable to the percentage, reported by other authors, analyzing the lipid-lowering properties of rosuvastatin. Olsson et al. showed that rosuvastatin $10-40 \mathrm{mg}$ could reduce TC and LDL-C levels by $34-65 \%$, whereas Brown et al. demonstrated their decrease by 39 $47 \%$ even with rosuvastatin $5-10 \mathrm{mg}[5,17]$.

Elevated liver enzymes (AST and ALT), myopathy, rhabdomyolysis and new-onset diabetes are the main adverse events that could occur in the course of statin treatment. According to published data simvastatin and pravastatin appear to have the best safety profiles. Simvastatin was associated with a decreased likelihood of stopping treatment because of adverse events in head-to-head trials with atorvastatin - odds ratio (OR) $0.61,95 \%$ confidence interval (CI) $0.42-0.89$ and rosuvastatin (OR $0.49,95 \%$ CI $0.27-0.88$ ) [15-19]. In drug-level network meta-analyses the odds of discontinuation were lower with pravastatin (OR $0.68,95 \%$ CI 0.52-0.91) and simvastatin (OR 0.75, 95\% CI 0.59-0.95) compared to atorvastatin [20-23]. 
Citation: Naydenov SN, Runev NM, Manov EI, Shabani RA, Donova TI (2014) Lipid-Lowering Potency and Tolerability of Generic Rosuvastatin in Bulgarian Patients with High and Very High Risk. J Cardiovasc Dis Diagn 2: 162. doi:10.4172/2329-9517.1000162

In our study a very high tolerability to ROSWERA ${ }^{\bullet}$ was found - no adverse events were reported by the patients and their treating physicians. The levels of liver enzymes and CK remained practically unchanged (insignificant dynamics) in the course of treatment, no patients reported for myalgias and no cases of new-onset diabetes were diagnosed. Our results, regarding safety of rosuvastatin treatment are consistent with data from other clinical studies. Shepherd et al. [24] assessed safety and tolerability of rosuvastatin, using data from 16,876 patients from 33 clinical trials. Rosuvastatin $5-40 \mathrm{mg}$ was associated with an adverse event profile similar to these one for atorvastatin 10$80 \mathrm{mg}$, simvastatin $10-80 \mathrm{mg}$ and pravastatin $10-40 \mathrm{mg}$. Clinically significant elevations, i.e. $>3$ times the upper limit of normal (ULN) in ALT were uncommon $(\leq 0.2 \%)$ in rosuvastatin and comparator statin groups. Elevated CK $>10 \times$ ULN occurred in $\leq 0.3 \%$ of patients, receiving rosuvastatin $\leq 40 \mathrm{mg}$ or other statin [24].

García-Rodríguez et al. [25] analyzed mortality and the hospitalization rate for myopathy, rhabdomyolysis, acute renal failure (ARF) and acute liver injury in $>100000$ patients, treated with statins, of which $>10000$ were receiving rosuvastatin. No cases of myopathy, rhabdomyolysis or acute liver injury occurred among rosuvastatin users. There were 2 cases of ARF [25].

In our study the compliance to treatment with ROSWERA ${ }^{\oplus}$ is also very high. All patients continued the prescribed statin therapy without interruption for the follow-up period and 43 of them (95.6\%) expressed their willingness to continue treatment with ROSWERA ${ }^{\circ}$ further. Physicians, treating the patients in this study were asked about the necessity of intermediate dose of ROSWERA ${ }^{\oplus}$. According to their answer $16(35.6 \%)$ of the patients will benefit a dose of $15 \mathrm{mg}$ daily and $2(4.4 \%)$ of them - $30 \mathrm{mg}$ daily to reach the target LDL-C level.

Finally, our study is small-sized, non-randomized and uncontrolled, i.e. we are restricted to make general conclusions about the entire population treated with this generic rosuvastatin. The 1-year results of patients treated with ROSWERA ${ }^{\circ}$ and followed up by us are promising and they imply the advantages of this new option of statin treatment for patients with high and very high CV risk. However further randomized and controlled clinical studies, including larger number of patients and head-to-head comparison with the original rosuvastatin CRESTOR ${ }^{\circ}$ are needed to elucidate the benefits of ROSWERA ${ }^{\circ}$ in daily clinical practice.

\section{Conclusion}

The generic rosuvastatin ROSWERA ${ }^{\oplus}$ prescribed at dosage $10 \mathrm{mg}$ and $20 \mathrm{mg}$ proved to be safe and efficacious lipid-lowering agent. Based on the results of this non-randomized pilot clinical study treatment with this statin seems to be cost-effective option of the therapeutic approach to patients with high and very high cardiovascular risk.

\section{Limitations}

1. A placebo control group was not included since our study was directed to patients with high and very high cardiovascular risk. Statins are a major class of drugs with proven benefits for such patients (first-line medication in the guidelines) - the placebo controls would not definitely benefit in these circumstances.

2. A control cohort treated with another type of statin was also not included since our study is focused on examination of a new generic rosuvastatin, which had just been introduced in Bulgaria, i.e. we did not intend to compare the potency and safety of a rosuvastatin to another statin.
3. A control cohort, treated with original rosuvastatin $\mathrm{CRESTOR}^{\circ}$, was not evaluated since we planned this study to be closest to the real clinical practice in Bulgaria. After being discharged from the hospital, the patients in our study provide the statin by themselves. The price of the CRESTOR ${ }^{\oplus}$ is 4 times higher than the generic forms and this is the main reason for the most patients to stop treatment. If we had compared CRESTOR to ROSWERA, the two groups would have been positioned at unequal financial conditions - this could have influenced the study results in terms of compliance to the treatment.

\section{References}

1. Reiner Z, Catapano AL, De Backer G, Graham I, Taskinen M, et al. (2011) ESC/EHS Guidelines for the management of dyslipidaemias. European Heart Journal 32: 1769-1818.

2. Cholesterol Treatment Trialistsâ€ ${ }^{\mathrm{TM}}$ (CTT) Collaboration, Baigent $\mathrm{C}$, Blackwel L, Emberson J, Holland LE, et al. (2010) Efficacy and safety of more intensive lowering of LDL cholesterol: a meta-analysis of data from 170,000 participants in 26 randomised trials. Lancet 376: 1670-1681.

3. Lopez LM (2005) Rosuvastatin: a high-potency HMG-CoA reductase inhibitor J Am Pharm Assoc (2003) 45: 503-513.

4. Schneck DW, Knopp RH, Ballantyne CM, McPherson R, Chitra RR, et al. (2003) Comparative effects of rosuvastatin and atorvastatin across their dose ranges in patients with hypercholesterolemia and without active arterial disease. Am J Cardiol 91: 33-41.

5. Brown WV, Bays HE, Hassman DR, McKenney J, Chitra R, et al. (2002) Efficacy and safety of rosuvastatin compared with pravastatin and simvastatin in patients with hypercholesterolemia: a randomized, double-blind, 52-week trial. Am Heart J 144: 1036-1043.

6. Tran YB, Frial T, Miller PS (2007) Statin's cost-effectiveness: a Canadian analysis of commonly prescribed generic and brand name statins. Can J Clin Pharmacol 14: e205-214.

7. Jick H, Wilson A, Wiggins $P$, Chamberlin DP (2012) Comparison of prescription drug costs in the United States and the United Kingdom, Part 1: statins. Pharmacotherapy 32: 1-6.

8. Mainar AS, Artieda RN (2010) [Influence of substitution of brand name fo generic drugs on therapeutic compliance in hypertension and dyslipidemia] Gac Sanit 24: 473-482.

9. Cheetham TC, Chan J, Benson V, Richmond C, Levin E, et al. (2005) Successful conversion of patients with hypercholesterolemia from a brand name to a generic cholesterol-lowering drug. Am J Manag Care 11: 546-552.

10. Rahalkar AR, Ban MR, Hegele RA (2013) Clinical equivalence of proprietary and generic atorvastatin in lipid clinic patients. Can J Cardiol 29: 418-422.

11. Perk J, De Backer G, Gohlke H, Graham I, Reiner Z, et al. (2012) European Guidelines on cardiovascular disease prevention in clinical practice. European Heart Journal 33: 1635-1701.

12. ESC of Cardiology Guidelines desk reference (2012) Compendium of abridged ESC guidelines, Wolter Kluwer. Lippincott Williams \&Wilkins.

13. Chong PH, Yim BT (2002) Rosuvastatin for the treatment of patients with hypercholesterolemia. Ann Pharmacother 36: 93-101.

14. Gould AL, Rossouw JE, Santanello NC, Heyse JF, Furberg CD (1998) Cholesterol reduction yields clinical benefit: impact of statin trials. Circulation 97: 946-952.

15. Haïat R, Leroy G (2011) Prescription guidelines in cardiology, (3rdedn) FrisonRoche, Paris.

16. Jones PH, Davidson MH, Stein EA, Bays HE, McKenney JM, et al. (2003) Comparison of the efficacy and safety of rosuvastatin versus atorvastatin simvastatin, and pravastatin across doses (STELLAR* Trial). Am J Cardiol 92 152-160.

17. Olsson AG, Pears J, McKellar J, Mizan J, Raza A (2001) Effect of rosuvastatin on low-density lipoprotein cholesterol in patients with hypercholesterolemia. Am J Cardiol 88: 504-508.

18. Expert panel on detection, evaluation, and treatment of high blood cholesterol 
Citation: Naydenov SN, Runev NM, Manov EI, Shabani RA, Donova TI (2014) Lipid-Lowering Potency and Tolerability of Generic Rosuvastatin in Bulgarian Patients with High and Very High Risk. J Cardiovasc Dis Diagn 2: 162. doi:10.4172/2329-9517.1000162

in adults (2001) Executive summary of the third report of the national cholesterol education program (NCEP) expert panel on detection, evaluation and treatment of high blood cholesterol in adults (adult treatment panel III). JAMA 285: 2486-2497.

19. Roach A, Tsikouris J, Haase K (2002) A new HMG-CoA reductase inhibitor for hypercholesterolemia. Formulary 37: 179-185.

20. Brugts JJ, Yetgin T, Hoeks SE, Gotto AM, Shepherd J, et al. (2009) The benefits of statins in people without established cardiovascular disease but with cardiovascular risk factors: meta-analysis of randomised controlled trials. BMJ 338: b2376

21. Mills EJ, Rachlis B, Wu P, Devereaux PJ, Arora P, et al. (2008) Primary prevention of cardiovascular mortality and events with statin treatments: a network meta-analysis involving more than 65,000 patients. J Am Coll Cardiol 52: $1769-1781$.
22. Jones $P$, Kafonek S, Laurora I, Hunninghake D (1998) Comparative dose efficacy study of atorvastatin versus simvastatin, pravastatin, lovastatin, and fluvastatin in patients with hypercholesterolemia (the CURVES study) Am J Cardiol 81: 582-587.

23. Kapur NK, Musunuru K (2008) Clinical efficacy and safety of statins in managing cardiovascular risk. Vasc Health Risk Manag 4: 341-353.

24. Shepherd J, Vidt DG, Miller E, Harris S, Blasetto J (2007) Safety of rosuvastatin update on 16,876 rosuvastatin-treated patients in a multinational clinical trial program. Cardiology 107: 433-443.

25. García-Rodríguez LA, Massó-González EL, Wallander MA, Johansson S (2008) The safety of rosuvastatin in comparison with other statins in over 100,000 statin users in UK primary care. Pharmacoepidemiol Drug Saf 17 943-952. 